\title{
Bangladesh HIV/AIDS communication challenges and strategies
}

\author{
Muhiuddin Haider ${ }^{1}$, Shamsun Nahar Ahmed ${ }^{2}$ and Nilufar K. Jaha ${ }^{2}$ \\ ${ }^{1}$ School of Public Health, University of Maryland, College Park, MD 20742, USA; ${ }^{2}$ Research Training \\ Management International, Gulshan 1, Dhaka, Bangladesh.e-mail: mhaider@umd.edu
}

\begin{abstract}
Bangladesh is in a precarious position in relation to the HIV/AIDS epidemic. Rates are currently low compared to the rest of the South Asian region, and the disease is relatively confined to small, highrisk populations - mainly injection drug users (IDUs) and commercial sex workers. Yet if steps are not taken quickly to keep the epidemic in check, it could easily spread to the general population as it has in other countries nearby. This would both increase the negative impact of HIV/AIDS and make it much harder to target for containment. It is therefore imperative that healthy behavior be promoted among IDUs and sex users, not only for their own health, but for the health of the country. Prevention will be the key to halting the spread of HIV infection through the implementation of communication and education programs aimed to change high-risk behavior. However, the disparate number of HIV/AIDS prevention programs independently operating in Bangladesh combined with the difficulty in adequately targeting this unique population of IDUs and sex workers establishes a complex situation where attaining behavior change is extremely difficult. This paper proposes adoption of the FOMENT model to design a health communication campaign targeting the high-risk populations in Bangladesh.
\end{abstract}

The situation in South and Southeast Asia: The HIV prevalence rate is still relatively low in Southeast Asia, but it is one of the most rapidly growing HIV/AIDS epidemics globally. Because of the largest population base and presence of several risk factors that enhance the spread of HIV, including poverty, gender inequality and social stigma, the Southeast Asia Region (Table I) is increasingly likely to suffer the brunt of the epidemic ${ }^{1}$. AIDS cases are largely underreported in the region. Therefore, the situation is likely to be much worse than the numbers tell.

Table 1. HIV burden in Southeast Asian region countries ${ }^{1}$

\begin{tabular}{lcc}
\hline Country & $\begin{array}{c}\text { HIV Prevalence in } \\
2004\end{array}$ & Estimated AIDS cases \\
\hline Bangladesh & $<0.2$ & $<1,000$ \\
India & 0.9 & 770,000 \\
Indonesia & 0.1 & 11,500 \\
Nepal & 0.5 & 7,800 \\
Thailand & 1.5 & 114,000 \\
\hline
\end{tabular}

Bangladesh may be able to learn from the successes and shortcomings of neighboring countries that have faced similar challenges in the fight against HIV/AIDS. India offers a case study, as it has a higher HIV rate than Bangladesh, with approximately 0.9 percent of the adult population
HIV positive in $2003^{2}$. Prevalence is highest among the 15-49 year-old age range, and the virus is primarily transmitted sexually ${ }^{3}$. However, transmission through injection drug use is rapidly increasing; the World Bank found that HIV prevalence among injection drug users (IDUs) was 55 percent countrywide and 67 percent in the Indian state of Manipur- near the Bangladeshi border. This rate increased rapidly, from zero cases reported between 1986 and September 1989, to more than 2,000 cases (54 percent of those sampled) between October 1989 and June $1990^{4}$. Surveillance data shows that the virus has started to spread from high-risk groups to the general population and move from urban to rural areas ${ }^{4}$.

In the early years the national government denied the threat of HIV/AIDS, leaving prevention programs in the hands of the individual states. In 1992-1997 the national government stepped in and started taking control, but the emphasis was still primarily through a medical model. Beginning in 1998, the program became more decentralized, with a focus on high-risk target groups such as commercial sex workers (CSWs), truck drivers, and IDUs. As India is among the countries which began preventive action early, a move that is essential to slow the spread of HIV/AIDS, particularly in such a populous nation, they have 
been so far able to maintain a relatively low national adult HIV prevalence rate.

Other countries in the South Asian region with low condom use, such as Nepal (where 39.5 percent of the people use condoms), have shown a rapid rise in HIV among sex workers in the past decade- from 1 percent in 1992 up to 17 percent in $2002^{5}$. In Nepal, the 2002 national HIV rate was 0.5 percent of the population between ages 15-49 years, along with 68 percent of IDUs and 17 percent of CSWs testing positive. In response, the Nepalese government started a National AIDS Prevention and Control Program in 1987. The country then adopted a strategic plan in 1997 which sought to broaden the response beyond the Health Ministry to integrate other sectors. The goal of this plan was to increase awareness of and response to social factors contributing to HIV/AIDS such as mobility, urbanization, labor migration, poverty, and the open India border. However, this approach has not been widely implemented, and the HIV rate among IDUs in Nepal skyrocketed due to a lack of surveillance ${ }^{6}$.

Both Jakarta in Indonesia and Katmandu in Nepal experienced a similar slow start to what are now serious HIV epidemics. In both of these cities, HIV is prominent among IDUs, and 10 percent of the male population uses commercial sex workers (compared to five percent in Bangladesh). Katmandu, in particular, mistakenly assumed that the HIV rate would remain low until a 1998 police crackdown of 114 IDUs found that 94 of them were HIV positive. HIV prevalence in the Katmandu IDU population is currently estimated at 68 percent $^{7}$.

Success of Uganda's ABC model on HIV control: ABC model stands for Abstinence (A) ' $B e$ faithful' (B), Condoms (C): Uganda has received significant international attention due to its HIV prevention success. Changes in sexual behavior included delayed sexual debut among adolescents, reductions in partner numbers, increased marital fidelity and increased condom use among casual partners. The most significant of these appears to be faithfulness or partner reduction behaviors by Ugandan men and women, whose reported casual sex encounters declined by well over $50 \%$ between 1989 and 1995. In addition, the median age of sexual debut increased from 14 years to 17 years. These figures provide ground to believe that significant behavior change occurred in Uganda. Be- faithful (B): Data from two cross sectional demographic and health surveys (DHS), conducted in 1989 and 1995, which showed a reduction of $60 \%$ in respondents who reported having had sex with a "non-regular partner" during the previous 12 months. Condoms (C) when used consistently and correctly, the male condom is effective for the reduction of sexual transmission of HIV and of other sexually transmitted infections (STIs). In Uganda, since the 1991 condom policy and strategy was enacted, regular condom use with non cohabiting partners rose from 5\% in 1987 to over $60 \%$ in $2002^{8}$.

The current HIV/AIDS situation in Bangladesh: With an estimated HIV prevalence of less than one percent, Bangladesh is still considered to be a low prevalence country. However, the similarity of behavioral patterns in Bangladesh in comparison to heavily affected regions in South and Southeast Asia suggests a probable rapid increase in prevalence. With a population base nearing 150 million people, even a small increase of one percent in the rate of infection would result in an additional 1.5 million cases ${ }^{9}$. This possibility of heading towards uncontrollable epidemic proportions must be averted with appropriate preventive measures ${ }^{10}$.

The first case of HIV/AIDS in Bangladesh was detected in 1989, and since 1994, prevalence has steadily risen with approximately 11,000 people living with HIV/AIDS by $2005^{11,12}$.

Table II. HIV and AIDS Bangladesh situation

\begin{tabular}{lcc}
\hline Identified cases & 2006 & Total \\
\hline HIV cases & 216 & 874 \\
AIDS cases & 240 & 374 \\
AIDS death & 109 & 183 \\
Estimated HIV cases & 7,500 & \\
\hline
\end{tabular}

The most at-risk populations include IDUs, CSWs, babus (the regular boyfriends of CSWs), men who have sex with men (MSM), and migrant workers. Prevalence in this vulnerable population has tripled over the last six years. National survey data reveal an increase in HIV infection in IDUs from $1.8 \%$ in 2001 to more than $4.9 \%$ in $2005^{13}$. This remains just short of the 5 percent rate necessary to define a "concentrated epidemic" prevalence has jumped as high as $9 \%{ }^{14}$.

This data reveals Bangladesh at a crossroad. If epidemic control measures in at-risk populations are not rapidly addressed, it could easily endanger the rest of the country as it becomes a generalized epidemic. Seventy-seven percent of IDUs in Bangladesh generally share needles freely. In addition, the IDU population is growing. Each year for the past five years, $10-20$ percent of previously non-injecting drug users began injecting ${ }^{15}$. The rapid increase in infection rates in this vulnerable and growing population of individuals has 
important implications for the spread of the epidemic in the general population. IDUs act as an important bridge population. Not only do they move frequently between regions of Bangladesh, but also frequently interact with other populations in society including male and female sex workers, MSM, and transport and industry workers. Ninetyone percent of IDUs in non-intervention sites reported having sex with female sex workers, with 53\% admitting to never using condoms, and 64\% having unprotected sex with regular partners ${ }^{16}$. Furthermore, many participate in the illegal sale of blood, thus increasing the risk for the tainting of the national blood supply ${ }^{17}$. With knowledge of HIV transmission lacking, where $34 \%$ of IDUs do not know that HIV could be spread through needle sharing, and unaware of their own status, the potential for spread to the general population is significant.

Another highly vulnerable group with substantial risk behavior and transmission potential are CSWs, particularly female sex workers. Seventy-five percent of the client population reports not perceiving HIV as a threat. This is unsurprising since few show symptoms of the disease in its early stages. In practice, it means that sex worker clientele show little concern for protection and very little interest in condoms (Table III) ${ }^{18}$.

Table III. Percent condom use variation across countries in Asia ${ }^{18}$

\begin{tabular}{lc}
\hline Country & $\begin{array}{c}\text { \% Condom use (with all recent } \\
\text { clients) } 2002\end{array}$ \\
\hline Bangladesh & 2 \\
Jakarta, Indonesia & 10 \\
Philippines & 30 \\
Nepal & 54 \\
Tamil Nadu, India & 88 \\
Bangkok, Thailand & 90 \\
Cambodia & 92 \\
\hline
\end{tabular}

Contributing to the problem is that female sex workers in Bangladesh have the highest turnover of clients than anywhere in Asia ranging from 18 to 44 clients per week $^{19}$. That is, with the low rate of condom use, the more clients a worker serves, the more likely she is to become infected, and the more likely she is to infect others.

Male sex workers and hijras display extensive sexual networking as they have frequent sexual contact with truckers, rickshaw pullers, and IDUs, as well as men from other occupation groups who are also frequent clients of female sex workers. The reported average number of clients per week is 8 to 11, and more than $90 \%$ of MSM in Central and
Northeast regions reported more than 20 partners, excluding their wives in the past year, with the mean number of partners at 64 and 50 respectively. As with female sex workers, consistent condom use is very low.

Further compounding factors of the epidemic include geographic location and open borders, low levels of HIV/AIDS awareness and knowledge, gender inequities, poverty, and stigma and discrimination. Due to its close proximity and porous borders to parts of India and Myanmar with a generalized epidemic, and Nepal with a concentrated epidemic among IDUs, where both legitimate and informal traffic crosses regularly, Bangladesh remains in a vulnerable situation. Behavioral surveillance in Bangladesh revealed that most people who engage in high-risk behaviors do not know how the virus is transmitted, and are unaware of how their behaviors put them at risk ${ }^{20}$. Furthermore, in the male-dominated society of Bangladesh, the low status of women puts them at greater risk of contracting HIV. Married women who are faithful to their husbands are at a growing risk of HIV and STIs due to the behavior of men in engaging in acts with sex workers and practicing injection drug use. Even equipped with the knowledge of risk involved with their husband's behavior, they do not have the power to negotiate safer sex with their partners. An increasing number of women and girls are being driven into sex work due to poverty, and are putting them at risk for HIV acquisition. Additionally, in societies where girls and women are not empowered to think critically, make decisions, and solve problems, they lack the self-efficacy needed to protect them against HIV.

The National response: Though Bangladesh can boast a low HIV rate today, the distribution of risk behaviors is such that the country may see continued transmission among high-risk groups and, eventually, a generalized epidemic. This underscores the urgency to make a concerted effort to counter the epidemic through a multisectoral effort. With this in mind, the government of Bangladesh has taken measures to address the issue, including the creation of the National AIDS Committee (NAC) in 1985 to ensure policy direction and promote efforts in HIV/AIDS. The National AIDS and STD Program is the government body currently charged with the coordination of policy and programs. The new National Strategic Plan for HIV/AIDS for the period 2004-2010 further outlines five program objectives to address HIV/AIDS prevention, treatment, and care $^{21}$. Government recognition of the problem and their efforts on policy is a significant achievement, but challenges still remain 
in the enforcement and application of policy for promotion, prevention, and treatment activities.

National policies, frameworks, and guidelines are comprehensive in nature, but implementation and success appears slow and incomplete ${ }^{22}$. There is a need for more specific policies to ensure appropriate and effective institutional and organizational scale-up of a multisectoral and comprehensive response. It has been documented that programs of 385 NGOs throughout the country are working on HIV/AIDS/STI programs, with $75 \%$ having specialized programs for specific groups, and the remainder with a broader framework. However, implementation of efforts are occurring in different geographical areas in an uncoordinated and overlapping manner without system-wide prioritization, coordination, or information sharing. As a result, there are gaps in coverage of vulnerable groups.

A critical component of the national and coordinated response to the growing epidemic is an effective communication strategy and response measure for HIV/AIDS prevention, care, and support in the country. Low levels of awareness and knowledge continue to exist and preventable risk factors continue to propagate the disease ${ }^{23}$. Only seventeen percent of most-at-risk populations have correct knowledge about prevention and misconceptions of HIV/AIDS. Among adolescents and young people of age 15-24, one out of three males in urban and one out of four in rural areas have correct knowledge regarding HIV and AIDS $^{24}$.

The communication strategies of Bangladesh, including the National HIV/AIDS Communication Strategy 2005-2010 ${ }^{25}$ and the Strategic Communication Plan for the HIV/AIDS Prevention Project (HAPP) Advocacy and Communication Component (ACC) ${ }^{26}$ both include integral elements for a more integrated and strategic approach to addressing HIV/AIDS prevention, care, and support through BCC, advocacy, and social mobilization. They recognize the basic needs to target vulnerable groups, improve the knowledge base, successfully link knowledge with risk perception and preventive behavior, and increase service-seeking behavior.

A divided and decentralized service delivery system in Bangladesh amongst the public, private, and NGO sectors further creates an uncoordinated challenge. HAPP-ACC calls for social mobilization at all levels of national state, district, and local government, including civil society and NGOs. However, the uncoordinated nature of interventions at the community level has lacked a quality of standard in their communication components, and to date, there has been little linkage of these efforts to each other and to mass media ${ }^{25}$. Furthermore, there is a great need for linking information to services. Communicating awareness and knowledge is an integral part of HIV prevention efforts. However, these communication efforts mean little without equipping targeted populations with the ability and power to act; encouraging the life skills needed to respond; and creating an enabling environment to sustain the change.

Responding: The value of the Diffusion of Innovations and FOMENT Models: The coordination and effectiveness of HIV/AIDS prevention programs in Bangladesh, and particularly those targeted to unique population groups can be enhanced through a long-term investment in health communications. Communication is a key factor in reducing and halting the spread of HIV/AIDS. A number of health communication initiatives currently exist in Bangladesh in the form of behavior change communication (BCC) and information, education, and communication (IEC) programs. For example, Family Health International with funding from USAID has created peer education programs through the Implementing AIDS Prevention and Control Activities (IMPACT) project that works towards HIV/STI prevention through focusing on high-risk groups ${ }^{27}$. The Health Communication Partnership and UNICEF co-funded and collaborated on a 26-episode TV drama with supporting TV and radio spots, billboards, and print materials to inform and motivate the general population on HIV prevention, care, and support ${ }^{28}$. During the $18^{\text {th }}$ World AIDS Day, the National AIDS/STD Program scaled up its communication efforts in collaboration with CARE Bangladesh and inundated communication channels with information about HIV/AIDS. Channels of communication included electronic and print media, souvenirs such as coat pins and T-shirts, infomercials, talk shows, documentaries, and open dialogue by famous persons ${ }^{29}$. These activities show that while health communication programs for HIV/AIDS exist in Bangladesh, they may only be short-term and moreover, there is no strategic coordination between implementing organizations. Behavioral surveys of the population show that they are not achieving the impact needed for the effective diffusion of knowledge and behavior change.

According to Tim Brown's Asian Epidemic Model, two major factors determining whether an HIV/AIDS outbreak occurs includes the existence of an epidemic among IDUs and high levels of CSW patronage. According to this model, the rapid 
rise of HIV infection in Thailand and Cambodia resulted from their 20 percent level of CSW use ${ }^{30}$. In Bangladesh, the commercial sex industry continues to grow, though at a slower rate than either Thailand or Cambodia. More than half of IDUs do not have access to interventions, and some who are able to access needle sharing programs do not take advantage of them ${ }^{31}$.

Since HIV is currently concentrated within the IDU population in Bangladesh, this population must be targeted to reduce its levels of needle sharing and unprotected sex. In addition, CSWs and their clients must be targeted to increase levels of condom use. If these key points of entry for HIV to the general population can be blocked, the epidemic may be contained. In Bangladesh, the concentration of the epidemic among CSWs and injection drug users is significant as they are considered unique populations. Unique populations have been found to act as powerful change agents for, or against, change by choosing to amplify or weaken communication messages ${ }^{32,33}$. Moreover, these populations often do not trust authority figures, and so the coordinating outreach organizations must be well-received in the community, and must be able to relate to the population.

Unique populations primarily bond through closely knit interpersonal relationship with those they perceive to share similar qualities, mostly within their own population members. The channels of communication to which they often pay more attention include specialty media, interpersonal peer networks, one-on-one counseling, or other highly targeted information dissemination ${ }^{34}$. It is important to recognize that these unique populations may not have access to various media and services typically offered by HIV/AIDS prevention programs. They might not have access to public service announcements on TV or radio, entertainment-education shows on TV or radio, hotlines, or programs that are run in conjunction with school, government agencies, or NGOs.

This paper recommends the FOMENT approach to behavior change communication for an HIV/AIDS intervention. FOMENT is a complementary development of Everett Rogers' Diffusion of Innovations Theory (DOI) ${ }^{35}$. Diffusion of innovations focuses on the ways in which new ideas and innovations are spread throughout adopting populations. DOI classifies people along a timeline according to how quickly they adopt a new idea or behavior, categorizing them as innovators, early adopters, early majority, late majority, and laggards ${ }^{36}$. Rogers outlines five components that affect the differential rate of adoption: relative advantage, compatibility, complexity, trialability, and observability ${ }^{37}$. The innovation-decision process may be visualized as a continuum, moving from knowledge and persuasion to decision, implementation, and, eventually, confirmation $^{38}$. At the confirmation stage a person will either fully adopt or fully reject the given innovation.

The diffusion of innovations theory has been criticized for not being adequately adaptive to communication processes in highly unique cultures and subcultures ${ }^{39}$. Most prevention programs utilize a blanket approach in reaching a general population, as seen in programs in Thailand, and do not use specific audience characteristics to target their outreach efforts ${ }^{40}$. Usually, this is due to the inaccessibility of the populations. Whereas mass media strategies are often utilized as initial information-spreading sources, these channels alone are often not enough to affect behavioral change. Interpersonal channels of communication are more effective in opening lines of communication and building trust between the target audience and the outreach worker ${ }^{41}$. The DOI concepts of homophily and opinion leadership are important in facilitating this channel because of their inherent characteristics of trust, respect, and influence.

Despite the merits and applications of DOI to effective communication programs among unique populations, it has been criticized for not working to "maximize the rate and scope of diffusion [in an] operational paradigm"12. FOMENT takes a more operational level approach than DOI, looking systematically at what is needed for a change agent to successfully facilitate the process of diffusion, and facilitating a multisectoral response. The FOMENT model "strives to bring about adoption of ideas in an organizational level," rather than only looking at the individual level ${ }^{14}$. It also emphasizes the proactive involvement and cooperation of agencies such as governments and non-profit organizations, to assail the same public health issue with a multifaceted approach. The acronym FOMENT stands for Focus, Organization, Management, Environment, Network, and Technology. Each of these elements is important when designing a behavior change mechanism.

Each element of FOMENT is further delineated using the innovation targeted to IDUs and CSWs and their clients respectively, that reducing needle sharing and increasing condom use to prevent disease. Focus means the clear delineation of the behavior change desired. In this case, the use of 
clean needles and condoms, and on a secondary level, a reduction in the patronage of CSWs and a reduction in drug users who switch to injecting. Organization refers to the organization of the behavior change program. Here the program should involve campaigns to convince IDUs, CSWs, and clients to practice disease-preventing behaviors. They must be specifically targeted, and incorporate sufficient methods known to work in unique populations, such as interpersonal communication. The program must also build or improve the infrastructure to facilitate these changes, such as availability of condoms, clean needles, and counseling. Management refers to the structures-governmental and social--that must approve and support the behavior change in order for it to be successful. In this case, the Bangladesh government and local religious leaders could participate in sponsoring and coordinating the program. Environment refers to determining and creating an environment that is conducive to behavior change, such as training injectors how to find new needles, training CSWs and clients how to effectively use condoms, educating the public about the risks of HIV/AIDS, providing free condoms to CSWs, and convincing non-injecting drug users not to start injecting. Network means looking at the ways in which innovations are currently diffused among the target populations, in terms of who is influential and who has power, and tapping those connections to reach others. For sex workers, it may be the brothel owners, for drug users, the drug providers. Finally, technology refers to the technological methods of diffusing the innovations, such as radio and television campaigns. Working through FOMENT, we can greatly improve the chances of containing HIV by reducing high-risk behaviors among community sex workers and injection drug users.

Factors to consider while designing a successful health communication campaign include "opportunities for behavior change, the reach of communication channels, and the fit of messages with audience's worldview"41. For the campaign targeting IDUs, professional injectors should be trained in the dangers of needle sharing and the availability of clean needles. Professional injectors are paid to inject IDUs with the drug injecting shop's equipment, and one set of equipment is often available in the shop that is shared among customers $^{42}$. When an intervention in northwest Bangladesh trained professional injectors, the result was a marked decrease in needle sharing. HIV among this subpopulation is nearly nonexistent today ${ }^{6}$. A crucial component in targeting CSWs on the other hand, is ensuring the widespread availability of condoms, preferably for free and distributed directly to the brothels.

A successful HIV intervention must also take into account broader socioeconomic factors that contribute not only to HIV infection, but to the phenomena of commercial sex work and injection drug use in the first place. Poverty and gender inequality, as well as the prevalence of sexual violence, play pivotal roles in these situations. As a theory, DOI has been criticized for its "individual blame bias," in which there is a tendency to blame the person for not adopting an innovation rather than holding the larger system accountable ${ }^{14}$. "The variables used in diffusion models to predict innovativeness are conceptualized so as to indicate the success or failure of the individual within the system rather than as indications of success or failure of the system (italics original),"14. In the DOI model, structural and environmental factors--such as poverty, education, or lifestyle--that influence a person's behavior are not taken into consideration $^{13}$. Health communications is a longterm investment which, according to a UNAIDS supported framework for HIV/AIDS communication, incorporates five contextual domainsgovernment policy, socioeconomic status, culture, gender relations, and spirituality ${ }^{43}$. FOMENT provides a framework into which these elements can be incorporated.

The near absence of DOI in HIV/AIDS related literature might be explained in that "DOI recognizes context as an important factor but does not provide explicit guidance on addressing the social, cultural, and economic obstacles related to context"13. These contexts are particularly crucial in influencing sexual behavior. This is where FOMENT serves as a complement, influencing the design of public health campaigns to reflect the broader system in which the innovation takes place.

Conclusion: AIDS was the fourth leading cause of death globally, if HIV can be prevented in high risk populations, it can be contained before it reaches the general population. In most developing countries, including Bangladesh, the stage is set for an epidemic to ignite. Factors like abject poverty, poor infrastructure, low awareness and inadequate sex education, coupled with women's inability to negotiate the conditions under which they have sex, all contribute to a situation in which HIV can spread rapidly. The FOMENT model provides an approach in which effective public health campaigns may be designed to target the high risk population in Bangladesh. Utilizing FOMENT's organizational-level components, and DOI's individually focused labels, the complementary 
nature of these theories translates to a greater array of tools for designing and implementing successful behavior change programs.

\section{References}

1. World Health Organization. Regional Office for SouthEast Asia. HIV/AIDS Facts and Figures. Information updated 10 August 2005. Available at: http://w3.whosea.org/en/Section10/Section18/Section34 8_9917.htm. Accessed June 16, 2005.

2. Indian HIV and AIDS Statistics. Available at: www.Avert.org/indiaaids.htm. Accessed June 16, 2005.

3. The World Bank. Regional Update. South Asia Region (SAR) - India. April, 2002.

4. The World Bank. Levels of HIV infection among injecting drug users. Available at: www.worldbank. org/aidsecon/confront/backgrnd/riehman/indexp2.htm. Accessed June 16, 2005.

5. Padam S. Trafficking and HIV/AIDS: The case of Nepal. Available at: http://hcc.med.vu.nl/artikelen/ simkhada. htm. Accessed June 17, 2005.

6. UNDP. Nepal at a glance. Available at: www.youandaids.org. Accessed June 17, 2005.

7. National AIDS/STD Program, DGHS, MOHFW Bangladesh. HIV in Bangladesh: Is Time Running Out? Background document for the dissemination of the fourth round (2002) of national HIV and behavioural surveillance. Dhaka; June 2003.

8. Uganda AIDS Commission www.aidsuganda.org

9. CIA, The World Fact Book, available at: http://www.cia.gov/cia/publications/factbook.

10. UNAIDS, 2006 Report on the Global AIDS Epidemic, May 2006, available at: http://www.unaids.org/en/HIV_data/2006GlobalReport/ default.asp.

11. USAID. Health profile: Bangladesh; April 2005, Available at: http://www.usaid.gov/our_work/ global_health/aids/Countries/ane/bangladesh_05.pdf.

12. UNAIDS, 2006 Report on the Global AIDS Epidemic, May 2006, available at: http://www.unaids.org/en/ HIV data/2006GlobalReport/default.asp.

13. UNGASS. Bangladesh national AIDS Committee UNGASS Indicators Country Report. Reporting period: January 2003 - December 2005.

14. USAID. Health Profile: Bangladesh; April 2005, Available at: http://www.usaid.gov/our_work/ global_health/aids/Countries/ane/bangladesh_05.pdf.

15. $4^{\text {th }}$ Round of the National HIV and behavioral surveillance (NASP, 2002-2003)

16. National AIDS/STD Program. Strategic Communication Plan for the HIV/AIDS Prevention Project (HAPP) Advocacy and Communication Component (ACC) 2004-2005. Directorate General of Health Services, Ministry of Health and Family Welfare, Government of the People's Republic of Bangladesh.
17. USAID. Health Profile: Bangladesh; April 2005, Available at: http://www.usaid.gov/our_work/ global_health/aids/Countries/ane/bangladesh_05.pdf.

18. Monitoring the Aids Pandemic (MAP). AIDS in Asia: Face the facts 2004. Available at: http://www.mapnetwork.org/docs/MAP_AIDSinAsia20 04.pdf. Accessed January 17, 2006.

19. World Health Organization. Regional Office for SouthEast Asia. Country Profile on Reproductive Health in Bangladesh 2003. Available at: http://w3.whosea.org/ LinkFiles/Reporductive_Health_Profile_chpbangladesh.pdf. Accessed January 17, 2006.

20. National AIDS/STD Program (NASP). National Strategic Plan for HIV/AIDS 2004-2010. Directorate General of Health Services, Ministry of Health and Family Welfare, Government of the People's Republic of Bangladesh, 2005.

21. National AIDS/STD Program (NASP). National Strategic Plan for HIV/AIDS 2004-2010. Directorate General of Health Services, Ministry of Health and Family Welfare, Government of the People's Republic of Bangladesh, 2005.

22. UNGASS. Shadow Reports 2006 - Bangladesh.

23. National AIDS/STD Program (NASP). National Strategic Plan for HIV/AIDS 2004-2010. Directorate General of Health Services, Ministry of Health and Family Welfare, Government of the People's Republic of Bangladesh, 2005.

24. National AIDS and STD Program (NASP) (2005). National HIV Serological Surveillance, 2004-2005; Bangladesh, MoHFW.

25. National HIV/AIDS Communication Strategy Situation Analysis - Bangladesh 2005-2010. Bangladesh: Ministry of Health and Family Welfare, Government of the People's Republic of Bangladesh.

26. Strategic Communication Plan for the HIV/AIDS Prevention Project (HAPP) Advocacy and Communication Component (ACC) 2004-2005. BCCP in collaboration with the Ministry of Health and Family Welfare, Government of the People's Republic of Bangladesh.

27. USAID. Health Profile: Bangladesh; April 2005, Available at: http://www.usaid.gov/our_work/ global_health/aids/Countries/ane/bangladesh_05.pdf.

28. Health Communication Partnership. HIV/AIDS Information. Available at: http://www.hcpartnership. org/Topics/hivaids.php

29. CARE Bangladesh. $18^{\text {th }}$ World AIDS Day. www.carebd.org

30. Brown T. Tracking Asia's HIV/AIDS epidemic. Available at: www.eastwestcenter.org/events-endetail.asp?news_ID=237. Accessed June 17, 2005.

31. Population and Health Infoshare. HIV surveillance in Bangladesh. Available at: www.phishare.org/documents/icddrb/1441/. Accessed June 17, 2005. 
32. Bracht, N. Applications to special populations: Case Studies. In: Health promotion at the community level. Bracht N. (ed). Newbury Park, CA, Sage, 1990.

33. Renn O. Risk communication and social amplification for risk. In: Communicating risk to the public. Kasperson RE, Stallen PJM (eds). Netherlands, Kluwer, 1981.

34. Dearing JW. Effective strategies of AIDS prevention programs in San Francisco. A research proposal funded by the Agency for Health Care Policy Research. East Lansing, MI, Michigan State University, 1993.

35. Rogers E. Diffusion of innovations. New York, The Free Press, 1995.

36. Haider M, Pal R, Al-Shoura S. FOMENT \& DOI: A Synergistic Theoretical Framework in Public Health Communication. In: Global Public Health Communication: Challenges, Perspectives, and Strategies. Haider M. Sudbury, MA, Jones and Bartlett, 2005, p 17.

37. Bertrand JT. Diffusion of Innovations and HIV/AIDS. J Health Communi. 2004; 9: 113-21.

38. Haider M, Kreps GL. Forty years of diffusion of innovations: Utility and value in public health. $\mathrm{J}$ Health Communi. 2004; 9: 3-11.
39. Dearing JW. Effective strategies of AIDS prevention programs in San Francisco. A research proposal funded by the Agency for Health Care Policy Research. East Lansing, MI, Michigan State University, 1993.

40. Svenkerud PJ, Singhal A. Enhancing the effectiveness of HIV/AIDS prevention programs targeted to unique population groups in Thailand: Lessons learned from applying concepts of diffusion of innovations and social marketing, J Health Communi. 1998; 3: 193-216.

41. Hornik RC, McDivitt J, Zimicki S, Yoder PS, Contreras-Budge E, McDowell J, Rasmuson M. Communication in support of child survival: Evidence and explanations from eight countries. In: Public Health Communication: Evidence for behavioral change. Hornik RC (ed). Mahwah, New Jersey, Laurence Erlbaum Associates, 2004, pp 219-48.

42. Reihman KS. Injecting Drug Use and AIDS in Developing Countries: Determinants and Issues for Policy Consideration. Available at: http://www. worldbank.org/aids-econ/confront/backgrnd/riehman/ index.htm. Accessed January 18, 2006.

43. UNAIDS. Communications framework for HIV/AIDS. 1999. Available at http://data.unaids.org/publications/ IRC-pub01/JC335-commFramew_en.pdf 
